Spectroscopic Observations of Reactions between Lactoflavin, the Coulter Compound, 'Cytochrome b', and Cytochrome $c$

From diphtheria toxin, one of us (M. D. E.) has prepared a solution continuing the "complex porphyrin" of Coulter ${ }^{1}$, and also a compound characterized by an $\alpha$-band located in the same position as that of cytochrome $b(563 \mathrm{~m} \mu)$. The preparation will be described elsewhere.

When oxidized lactoflavin was added to this solution, at $30^{\circ} \mathrm{C}$. and $p \mathrm{H} 7 \cdot 4$, the $574 \mathrm{~m} \mu$ and $563 \mathrm{m \mu}$ bands disappeared instantly. When lactoflavin was reduced by hydrosulphite, the. $574 \mathrm{~m} \mu$ and $563 \mathrm{m \mu}$ bands reappeared at once. The $574 \mathrm{~m} \mu$ and $563 \mathrm{~m} \mu$ compounds must therefore be in the reduced state.

Reduced cytochrome $c$ was added next to this solution. A paradoxical phenomenon was observed : the $574 \mathrm{~m} \mu$ and $563 \mathrm{~m} \mu$ bands again disappeared, as if reduced cytochrome $c$ had oxidized the reduced $574 \mathrm{~m} \mu$ and $563 \mathrm{~m} \mu$ substances. Cytochrome $c$ was obtained from a stock solution by acetone precipitation; the stock solution had been prepared in Prof. Keilin's laboratory by Dr. F. Stare.

In a separate experiment, oxidized cytochrome $c$ was added to the solution of $574 \mathrm{~m} \mu$ and $563 \mathrm{~m} \mu$ substances. All the bands remained unchanged, indicating that no reaction had occurred.

Lactoflavin is not necessary for the reaction between reduced cytochrome $c$ and the reduced $574 \mathrm{~m} \mu$ and $563 \mathrm{~m} \mu$ substances. This was shown by adding reduced cytochrome $c$ to the $574 \mathrm{~m} \mu$ and $563 \mathrm{~m} \mu$ compounds. The $574 \mathrm{~m} \mu$ and $563 \mathrm{~m} \mu$ bands disappeared. This reaction can be partly reversed by the immediate addition of a few drops of 5 per cent potassium ferricyanide solution. Oxidized cytochrome $c$ appears, and the $574 \mathrm{mu}$ and $563 \mathrm{mu}$ bands re-appear in diminished strength. The $574 \mathrm{m \mu}$ and $563 \mathrm{~m} \mu$ substances alone do not react with ferricyanide. A solution containing the $574 \mathrm{~m} \mu$ compound alone reacted exactly like the mixture of the $574 \mathrm{~m} \mu$ and $563 \mathrm{~m} \mu$ compounds.

The following hypothesis summarizes the observations and interprets the paradox: when the iron atom of cytochrome $c$ is in the divalent state, the $574 \mathrm{~m} \mu$ and $563 \mathrm{~m} \mu$ compounds can be oxidized by the porphyrin ring of cytochrome $c$; but when the iron is in the trivalent state, the porphyrin ring cannot oxidize the $574 \mathrm{~m} \mu$ and $563 \mathrm{~m} \mu$ substances.

These reactions between cellular catalysts are interesting in themselves. In addition, a more exhaustive investigation will bring out whether or not they are related to the Pasteur reaction.

School of Medicine,

Washington University, St. Louis, Mo.

${ }^{2}$ Coulter and Stone, J. Gen. Physiol., 14, 583 (1930/31).

\section{Oxidation of Cholesterol and Dehydroandrosterone by Means of Osmic Acid}

UNSATURATED compounds are known to add, under the action of osmic acid, two hydroxyl groups at the place of their double bond ${ }^{1}$, these groups being in cis-position with regard to each other. The reaction course is analogous to that produced by $\mathrm{KMnO}_{4}$. However, action of the latter on cholesterol ${ }^{2}$ yields but 4-5 per cent of cis-cholestan-triol. Thus $\mathrm{KMnO}_{4}$ is unsuitable for the oxidation of the double bond in sterol-derived hormones, in particular in dehydroandrosterone.

After we had obtained trans-androstan-(17)-one$(3,5,6)$-triol from dehydroandrosterone oxide ${ }^{3}$ we desired to obtain also the cis-compound for the sake of comparing their physiological activities. The method has been worked out for cholesterol ${ }^{4}$, then transferred to dehydroandrosterone.

Equivalent amounts of anhydrous cholesterol and osmic acid, dissolved in water-free ether, are allowed to react for 2-3 days. The ether is then distilled off and the black residue boiled with an aqueousalcoholic solution of $\mathrm{Na}_{2} \mathrm{SO}_{3}$ for two hours. When working with cholesterol only traces of the looked-for product-cholestan-triol-are found in the wateralcohol filtrate; most of it is obtained by extracting the black residue with boiling alcohol. The cis. cholestan-triol obtained melted, after washing with ether, at $238 \cdot 5-239 \cdot 5^{\circ}$. Mixed with the trans-com. pound it caused depression of the melting point.

On oxidizing dehydroandrosterone with $\mathrm{OsO}_{*}$ almost the whole of the androstanone-triol passes into the aqueous-alcoholic solution (after boiling with sulphite). Yield of the crude product : 70 per cent. Recrystallized from ethyl-acetate; transparent rectangular prisms, m.p. $243 \cdot 5-244^{\circ}$ (corr. ; sinters at $\left.242 \cdot 5^{\circ}\right)$. Analytical data agree with the formula $\mathrm{C}_{19} \mathrm{H}_{30} \mathrm{O}_{4}$.

We intend applying the same method also to androstene-diol, androstene-dione and testosterone.

The present work is to be published shortly in detail.

\section{Ushakov.}

A. LutenBerg.

Laboratory of Sterol and Hormone Chemistry, All-Union Institute of Experimental Medicine, Moscow.

${ }^{1}$ Details in the recent paper by Criegee, R., Ann., 522, 75 (1936), where the literature is cited.

Windaus, A., Ber., 40, 257 (1907).

"Ushakov, M., and Lutenberg, A., "Dehydroandrosterone oxide", in press in Journal Obshchei Chimii and Bull. Soc. Chim. de France.

- Criegee (loc. cit.) mentions having obtained some cis-diols of the sterol group ; he does not give any details, nor mention what sterols he worked with.

\section{Decomposition of Benzene-Diazonium Chloride}

To test the suggestion ${ }^{1}$ that the decomposition of aromatic diazo compounds might be non-ionic in mechanism, I have been investigating the decom. position of benzene-diazonium chloride in the presence of non-aqueous solvents. When suspended in an organic liquid, benzene, diazonium chloride appears to melt at about $50^{\circ} \mathrm{C}$. and then immediately a violent decomposition sets in. There is great heat evolution, and, except on the small scale, the reaction tends to become explosively violent. Often hydrogen chloride is evolved, and whenever its formation has been observed, chlorobenzene has been found amongst the reaction products.

From an examination of the decomposition in acetone, it appears possible that the chlorobenzene is produced by a secondary reaction between the decomposing benzene-diazonium chloride and the hydrogen chloride, since when an excess of chalk is added to keep the mixture neutral, the principal reaction that occurs is

$\mathrm{Ph} \cdot \mathrm{N}_{2} \cdot \mathrm{Cl}+\mathrm{CH}_{3} \cdot \mathrm{CO} \cdot \mathrm{CH}_{3}=\mathrm{N}_{2}+\mathrm{Ph} \cdot \mathrm{H}+$

$$
\text { Cl. } \mathrm{CH}_{2} \cdot \mathrm{CO} \cdot \mathrm{CH}_{3} \text {; }
$$

for both benzene and chloroacetone were isolated in good yield. 